\title{
Neonatal Seizures Characteristics and Prognosis
}

\section{Marija Knežević-Pogančev}

University of Novi Sad, School of medicine, Child and youth health care Institute of Vojvodina, Novi Sad, Hajduk Veljkova, Serbia

*Corresponding author: Marija Knežević-Pogančev, University of Novi Sad, School of medicine, Child and youth health care Institute of Vojvodina, Novi Sad, Hajduk Veljkova, Serbia, Tel: 38163 7789285; E-mail: mkp.marija@gmail.com

Received date: Aug 01, 2016; Accepted date: Sep 26, 2016; Published date: Sep 29, 2016

Copyright: (C) 2016 Knežević-Pogančev M. This is an open-access article distributed under the terms of the Creative Commons Attribution License, which permits unrestricted use, distribution, and reproduction in any medium, provided the original author and source are credited.

\section{Introduction}

Seizures are the most common neurological emergency in the neonatal period. Neonatal seizures are very often named neonatal convulsions even they do not present as convulsions. They are one of the most important diagnostic and therapeutic clinical challenges. They occur during neonatal period, from birth to the end of 28th day of life [1]. Seizures are more common in the neonatal period than at any other time during life. They appear mostly during the first 1-2 days, but usually during first week from birth. Neonatal brain is uniquely vulnerable to seizures. Usually they signify serious damage to the developing immature brain. There is also clear evidence that seizure can damage the brain and exacerbate pre-existing injury. Therefore it is very imperative to identify neonatal seizures and treat them as soon as possible.

\section{Epidemiology}

The prevalence of neonatal seizures is approximately $1-5 \%$. The overall incidence is 3 per 1,000 live births ( 57 to 132 per 1,000 live births in pre-term infants) [2].

\section{Etiology}

The etiology of neonatal seizures is diverse. Neonatal seizures are most often associated with perinatal hypoxia, hypoxic-ischemic encephalopathy, periventricular hemorrhage, cerebral infarction, infection and cerebral malformations. Hypoxic-ischemic encephalopathy is the most common cause. It causes $80 \%$ of all seizures in the first 2 days of life. They can be clinical presentation of genetic caused epileptic syndromes of early childhood. Acute metabolic disturbances, electrolyte and glucose abnormalities are now very rare causes of neonatal seizures (Table 1).

\section{Neonatal seizure type}

The most widely used scheme is by Volpe of five main types of neonatal seizure [3].

Despite the high prevalence of neonatal seizures, epileptic syndromes in neonates are rare and infrequent. International League against Epilepsy (ILAE) is defining as neonatal epileptic syndromes: [4]

$$
\begin{aligned}
& \text {-Benign familial neonatal seizures } \\
& \text {-Benign neonatal seizures (non-familial) } \\
& \text {-Early myoclonic encephalopathy } \\
& \text {-Ohtahara syndrome }
\end{aligned}
$$

\section{Neonatal seizure semiology}

Neonatal seizures are paroxysmal, repetitive and stereotypical events, mostly clinically subtle, inconspicuous and very difficult to recognize. Very high level of experience is necessary to differentiate neonatal seizures from the normal behaviors of the inter-ictal periods or physiological phenomena. Neonatal seizures do not present with clear clinically recognizable post-ictal state. Generalized tonic clonic seizures are exceptional. The duration of neonatal seizures is usually 10 $\mathrm{sec}$ to 1-2 min. They are mostly repetitive with a median of few minutes in between each seizure. Longer seizures and epileptic status develop more readily at this age, but convulsive neonatal epileptic status is not as severe as in older infants and children.

\begin{tabular}{|l|l|}
\hline Type & Clinical Signs \\
\hline Subtle (50\%) & $\begin{array}{l}\text { Ocular, oral-buccal-lingual, autonomic, apnea, } \\
\text { limb posturing and movements }\end{array}$ \\
\hline Clonic (25\%) & $\begin{array}{l}\text { Repetitive jerking, distinct from jittering, focal or } \\
\text { multifocal }\end{array}$ \\
\hline Myoclonic (20\%) & $\begin{array}{l}\text { Rapid isolated jerks, focal, multifocal or } \\
\text { generalized }\end{array}$ \\
\hline Tonic (5\%) & $\begin{array}{l}\text { Stiffening, decerebrate posturing, focal or } \\
\text { generalized }\end{array}$ \\
\hline $\begin{array}{l}\text { Non-paroxysmal repetitive } \\
\text { behaviors }\end{array}$ & $\begin{array}{l}\text { Different presentation hard to be recognized of } \\
\text { unknown statistic presentation }\end{array}$ \\
\hline
\end{tabular}

Table 1: Neonatal seizure type.

\section{Electroencephalography}

Electoencephalography is very helpful for neonatal seizure diagnosis, but it is not prognostic factor. The background EEG features of encephalopathy evolve over time. Normal background EEG with well-organized sleep stages has consistently been shown to be associated with an $80 \%$ chance of normal development. Low-voltage EEG seen longer than first 6 hours of life is poor prognostic factor. Neonatal seizures differ in electroencephalographic (EEG) characteristics to seizures in older children and adults. There are no clear data about correlation between the number of seizures and outcome [5]. There are suggestions that the outcome is worse with large number of independent electrographic seizure foci. The number of electrographic seizures is not in general an indicator of prognosis, nor is the clinical seizure type. Neonatal seizure prognosis is cause dependent. Neonatal seizure show higher mortality and morbidity for preterm neonates and in all pre/term neonates with hypoxic-ischemic encephalopathy, meningitis and cerebral malformations than hypocalcaemia, benign familial neonatal seizures, subarachnoid hemorrhage or stroke. Normal background EEG with well-organized 
Page 2 of 2

sleep stages has consistently been shown to be associated with an $80 \%$ chance of normal development. The background EEG features of encephalopathy evolve over time, so prognostic conclusions cannot be made early [6].

\section{Antiepiletpic Drugs}

Antiepileptic drugs (AEDs) do not give same effect as in older children and adults, according to different pathophysiology convulsions mechanism, and AED pharmacokinetics in neonatal period. There are not clear data about the potential adverse effects of currently used AEDs on brain development $[7,8]$.

\section{Neonatal Seizure Prognosis}

Neonatal seizure prognosis is cause dependent. Main factor determining outcome is the underlying cause and not the seizures themselves. Despite high mortality (approximately 15\%) and morbidity (approximately 30\%), one half of neonates with seizures achieve a normal or near-normal state. About $30 \%$ of neonates having seizures develop epilepsy [9]. Normal background EEG with well-organized sleep stages has consistently been shown to be associated with an $80 \%$ chance of normal development.

Delayed recognition of a treatable cause has significant impact on future child's neurological outcome. Neonatal seizures have an adverse effect on neurodevelopment and predispose to cognitive, behavioral or epileptic complications during postneonatal period. Seizures cause synaptic reorganisation with aberrant growth (mossy fibers), and may interfere with the normal synaptic pruning which takes place during development. If seizures are not controlled the electrical activity can continue to circulate (kindling). Prolonged seizures cause progressive cerebral hypoxia, changes in cerebral blood flow, cerebral edema and lactic acidosis causing severe brain damage [10-12].

Neonatal seizure prognosis depends largely on the cause of the seizures. They are being worse with higher mortality and morbidity for preterm neonates and for neonates having hypoxic-ischemic encephalopathy, meningitis and cerebral malformations than hypocalcaemia, benign familial neonatal seizures, subarachnoid hemorrhage or stroke [13]. Most often observed poor prognostic outcomes include periventricular malacia, brainstem damage, cortical atrophy with clinical observed cerebral palsy and microcephaly with significant learning difficulties.

Delayed recognition of a treatable cause has significant impact on future child's neurological outcome. For this reason prompt diagnosis, investigation and treatment are very important.

\section{References}

1. Arzimanoglou A, Guerrini R, Aicardi J (2004) Neonatal seizures. In: Arzimanoglou A, Guerrini R, Aicardi J, (eds.), Aicardi's epilepsy in children. Philadelphia: Lippincott Williams \& Wilkins.

2. Jallon P, Preus P (2013) The epidemiology of seizure disorders in infancy and childhood: definitions and classifications. In: O Dulac et al (eds.), Handbook of Clinical Neurology. Pediatric Neurology, Part 1 (3rd edn.), pp 381-398. Elsevier, Amsterdam, Netherlands.

3. Volpe JJ (1989) Neonatal seizures: current concepts and revised classification. Pediatrics 84: 422-428.

4. Yamamoto H, Okumura A, Fukuda M (2011) Epilepsies and epileptic syndromes starting in the neonatal period. Brain Dev 33: 213-220.

5. McBride MC, Laroia N, Guillet R (2000) Electrographic seizures in neonates correlates with poor neurodevelopmental outcome. Neurology 55: 506-513.

6. Douglas-Escobar M, Weiss MD (2015) Hypoxic-ischemic encephalopathy: a review for the clinician. JAMA Pediatr 169: 397-403.

7. Ento M, De Vries Ls, Alberola A (2010) Approach to seizures in the neonatal period: a European perspective. Acta Paediatr 99: 497-501.

8. Van Rooij LG, Hellstrom-Westas L, De Vries LS (2013) Treatment of neonatal seizures. Semin Fetal Neonatal Med 18: 209-215.

9. Sani F, Piccolo B, Cantalupo G (2012) Neonatal seizures and postneonatal epilepsy: a 7-y follow-up study. Pediatr Res 72: 186-193.

10. Boylan GB, Rennie JM, Chorley G (2004) Second-line anticonvulsant treatment of neonatal seizures A video-EEG monitoring study. Neurology 62: 486-488.

11. Silverstein FS, Ferriero DM (2008) Off-label use of antiepileptic drugs for the treatment of neonatal seizures. Pediatr Neurol 39: 77-79.

12. Johnston MV, Fatemi A, Wilson MA (2011) Treatment advances in neonatal neuroprotection and neurointensive care. Lancet Neurol 10: 372-382.

13. Douglas-Escobar M, Weiss MD (2015) Hypoxic-ischemic encephalopathy: a review for the clinician. JAMA Pediatr 169: 397-403. 